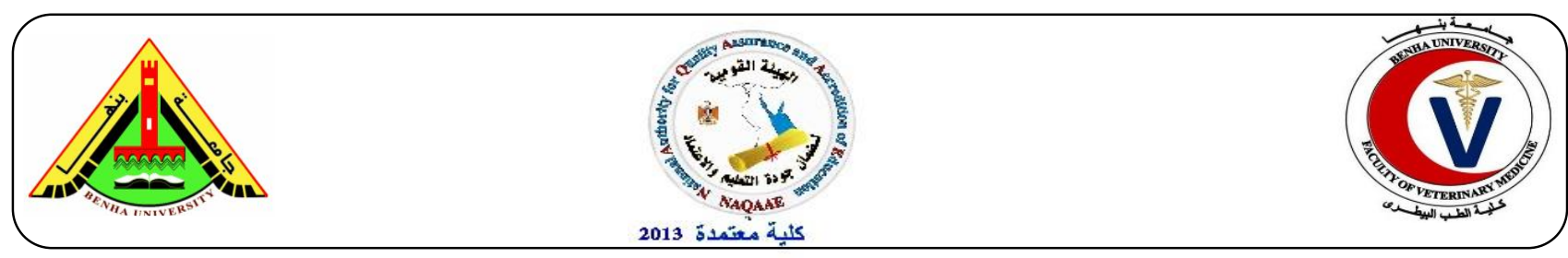

\title{
Interaction of some plant extracts with some antibiotics against E.coli from chickens
}

\author{
Ashraf A. Abd El- Tawab ${ }^{1}$, Ahmed A. Ammar ${ }^{2}$, Ahmed M. Hamouda ${ }^{3}$ and Salma S. El-Deen ${ }^{3}$ \\ ${ }^{1}$ Bacteriology, Immunology and Mycology Department, Faculty of Veterinary Medicine, Benha University, Egypt. \\ ${ }^{2}$ Microbiology Department, Faculty of Veterinary Medicine, Zagazig University, Egypt. \\ ${ }^{3}$ Animal Health Research Institute, Zagazig branch.
}

\section{A B S T R A C T}

Multidrug-resistant bacterial strains are becoming a serious problem, therefore, application of newer antimicrobial agents, as the plant extracts as a natural antimicrobial source combined with antibiotics as tried to overcome this problem. In-vitro methods as the Decimal Assay for Additivity (DAA) is being applied to define the end point for additivity, as the interactions are known on a mechanistic basis to be either additive or synergistic or antagonistic. The present study was carried out to evaluate the antimicrobial activity of five plant extracts prepared by the ultrasonic-assisted methanol extract (UAE) namely Rosmarinus officinalis L. (Rosemary), Origanum majorana L. (Marjoram), Mentha spicata L.(Mint), Anethum graveolens L.(Dill) and Azardirachta indica L.(Neem);combined with antibiotics like amoxicillin, doxycycline, gentamycin and difloxacin against 120 isolates from poultry, among them 79 isolates were belonging to E.coli by using agar diffusion method. The mean zones of inhibition $(\mathrm{mm})$ of methanol plant extracts and antibiotics were determined at different concentrations; also the minimum inhibitory concentration (MIC) of the plant extracts or the antibiotics or combination between them was determined by the twofold dilution method; while the antimicrobial activities were assessed by using disc diffusion method.Total phenolic content (TPC) of plant extracts was determined by the Folin-Ciocalteu method.Also the antioxidant activity of the extracts was determined by the 1,1-diphenyl-2-picryl-hydrazyl (DPPH) assay. Results revealed synergistic effects appear in rosemary with amoxicillin by ratio (7:3),(6:4) and gentamicin by ratio $(7: 3),(6: 4)$ and difloxacin with ratio $(7: 3),(6: 4),(5: 5)$ while Dill and amoxicillin by ratio (7:3) and gentamicin by ratio (7:3),(6:4),(5:5) and Peppermint with doxycycline only with $(7: 3),(6: 4),(5: 5)$.

Keywords: E.coli; antibiotics; plant extracts; TPC; antioxidant; DPPH; DAA.

(http://www.bvmi.bu.edu.eg)

(BVMJ-35(2): 107-119, 2018)

\section{INTRODUCTION}

Antimicrobial resistance is one of the most common serious threats facing poultry industry (Enayat et al., 2013) as it can transfer to other pathogenic bacteria, causing compromise in treatment of severe infections (Stefanovic \&
Comic, 2012).This problem has encouraged scientists to search for new alternatives to antibiotics (CDC 2013).

Gram-negative bacteria are more resistant to antibiotics than the Gram-positive bacteria due 
to the permeability barrier provided by the cell wall or to the membrane accumulation mechanism (Mounia et al., 2010).

To overcome this problem, some medicinal plants as source for multidrug resistance inhibitors (Eze et al., 2013) were utilized in an In-vitro test for antimicrobial agents used in combination with antibiotics that is DAA which is based on disc diffusion assay, designed to define the interactions if greater or less than additivity, which respectively, defined as synergism or antagonism.

The MIC is the lowest concentration of an antimicrobial that will inhibit the visible growth of a microorganism by overnight incubation, usually reported as $\mathrm{mg} / \mathrm{L}$ (Delaquis et al., 2002), it represents a monitor for resistance to antimicrobial agents and is carried out by broth dilution methods (Handa et al., 2008).

Nowadays, to overcome environmental pollution by aromatic plant extract residues, numerous studies focuses in recovering, recycling of residues as it has potential biologicals (Cioffi et al., 2009; Gavaric et al., 2015) as $99 \%$ of residues after extraction are rich with secondary metabolites and bioactive compounds e.g. natural antioxidants and phenolic compounds (Zhao and Gao, 2014) which play an important role in protection against infection, preventing oxidation and degenerative diseases (Singleton et al., 1965 and Valko et al., 2006). Finally, this study was carried out to evaluate the Interaction of some plant extracts with some antibiotics against E.coli from chickens and Determination of MIC, MBC for each antibiotics and plant extracts by using DAA method to detect effect of interaction between antibiotics and plant extracts and detection of antioxidant and total phenolic compound.

\section{Materials and methods}

\subsection{Bacterial strains:}

a) Standerd strain: the tested E.coli (ATCC 10536) were provided from the culture collections of the Microbiological Dept., National Research Center (NRC) Dokki, Giza, Egypt.

b) Field strain: 79 isolates out of 120 diseased poultry samples which isolated from different poultry farms in Dakahlia governorates (Mahtet Elsalam, Mahtet ElAml, Tawonya) and in Sharkia governorates (Gamsa, Sherbin, Elsalehia project).

\subsection{Plants:}

a) Plant materials: Five plant samples: rosemary leaves (Rosmarinus oficinalis), marjoram leaves (Origanum majorana), mint leaves (Mentha spicata), dill seeds (Anethum graveolens), neem leaves (Azadirachta Meliaceae) were obtained from Faculty of Agriculture., Zagazig University.

b) Preparation of the ultrasonic-assist methanol $80 \%$ extract:

Extraction was performed by ultrasound to overcome (time-solvent) consuming and increase extraction efficiency according to Betancount (2008).

2.3. Isolation and Identification of the suspected bacteria: in Animal Health Research Institute Zagazig lab, 79 poultry samples were subjected to biochemical identification described by Harley and Prescott (2002).

2.4. Antimicrobial susceptibility testing:

2.4.1. Disk Diffusion Method: was performed according to guidelines set by the Clinical Laboratory Standards Institute (CLSI, 2010). The diameters of the zones of inhibition were measured in millimeter and classified as resistant, intermediate or sensitive. The assay was repeated using plant extract alone, antibiotics alone or combination between them by disk diffusion method to detect the effect of ten standard antibiotic discs (Bauer et al., 1966) and five selected extracts (Oxoid $®$ ) against E.coli.

2.4.2. Minimal inhibitory concentration $(M I C)$ : the isolated strain matched the 0.5 
McFarland standard $\left(1.5 \times 10^{5} \mathrm{CFU} \mathrm{mL}^{-1}\right)$ and results of antibiotics and/or extracts showed no visible bacterial growth were considered as MIC and interpreted with recommendations of the National Committee for Clinical Laboratory standards (Lorian, 1996., Adam et al., 1998; Dorman \& Deans, 2000).

2.5. Evaluation of combined activity of antibiotics and extracts using Decimal Assay for Additivity (DAA):

As described by Sanders et al', (1993) to detect end point for additivity so that interactions greater or less than additivity defined as synergism and antagonism respectively.

\subsection{Determination of total phenolic} compounds (TPC):

Measured by UV spectrophotometer Škerget et al.,(2005) using Folin-Ciocalteu reagent AOAS, (1990) Results were expressed as mg gallic acid equivalents (GAE) per gram of dry weight (mg GAE g-1 DW) using a calibration curve and the Yield of extracts $(\mathrm{g} / 100 \mathrm{~g})$ for different plants.

\subsection{Antioxidant $D P P H^{\cdot}$ radical-scavenging} activity:

The ability of the extracts for electron donation was measured by bleaching of the purple colored solution of DPPH (2, 2-diphenyl-1picrylhydrazyl) to the yellow colored Gulcin et al., (2004). Color intensity varies according to the amount of oxidant in the sample. The absorbance of this color was measured spectrophotometrically at $530 \mathrm{~nm}$ Dikilitas et al., (2011).

\section{RESULTS}

This study focused on the incidence of E.coli in a total of 120 samples that were aseptically collected from visceral organs. Samples revealed 79 E.coli out of 120 specimens with percentages of $(65.8 \%)$.

Identification of Gram negative isolates, biochemical tests as IMVIC were used under standard conditions which discussed in Table
(4), as E.coli show negative results with Indole and Citrate and positive result with Indole and M.R.

Antimicrobial susceptibility testing showed highest sensitivity rate of E.coli strains to colistin, doxycycline and flurofinecol $(38,31$ and $27 \%$ ) respectively, intermediate sensitivty recorded to difloxacin, gentamycin and amoxicillin ( 54, 42 and 32\%) respectively; while the highest resistant rates were recorded to erythromycin, cefotaxime and streptomycin with ( 58, 53 and $42 \%$ ) respectively in (Table 5).

The clear zones around four antibiotic discs indicated organism's inability to survive in the presence of the test antibiotic antibacterial activity of natural antimicrobial agents (Rosemary, Majoram , Peppermint, Dill and Neem) with the lowest concentration had a ZI $8,15.2,15,0$ and $10 \mathrm{~mm}$, respectively.on the other hand antibiotics as (amoxicillin, doxycycline, gentamycin, difloxacin) exhibited different I.Z like 10-15 mm amoxycilin, 0-16 $\mathrm{mm}$ doxycycline, $13 \mathrm{~mm}$ around gentamycin and 18-19 mm difloxacin respectively against field isolate of E.coli in (Table 3).

The result of MIC of plant extract on field strain is compared with their results on standard strain as Rosemary was $(1 \mu \mathrm{g}$ on field and $0.25 \mu \mathrm{g}$ on standard), Peppermint was $(64 \mu \mathrm{g}$ on field and $16 \mu \mathrm{g}$ on standard), Majoram was $(4 \mu \mathrm{g}$ on field and $1 \mu \mathrm{g}$ on standard), Dill was ( $8 \mu \mathrm{g}$ on field and $2 \mu \mathrm{g}$ on standard), Neem was $(32 \mu \mathrm{g}$ on field and $8 \mu \mathrm{g}$ on standard).

The result of MIC of antibiotics on field strain is compared with their results on standard strain as AML was $(8 \mu \mathrm{g}$ on field and $4 \mu \mathrm{g}$ on standard), INN was ( $1 \mu \mathrm{g}$ on field and $4 \mu \mathrm{g}$ on standard), DO was $(0.5 \mu \mathrm{g}$ on field and $0.125 \mu \mathrm{g}$ on standard), GN was (16 $\mu \mathrm{g}$ on field and $4 \mu \mathrm{g}$ on standard). 
Abd El- Tawab et al. (2018). BVMJ-35(2): 107-119

Determination of synergistic effect between plant extracts and antibiotics was evaluated by comparing the size of inhibition zone of plant alone and antibiotics alone on E.coli with size of inhibition zone of plant extracts and antibiotics together as results revealed that synergistic effects appear in rosemary and amoxicillin with ratio $(7: 3),(6: 4)$, rosemary and gentamicin with ratio (7:3), (6:4),rosemary and difloxacin with ratio $(7: 3),(6: 4),(5: 5)$ while Dill and amoxicillin with ratio (7:3), Dill and gentamicin with ratio $(7: 3),(6: 4),(5: 5)$ and Peppermint with doxycycline only with ratio $(7: 3),(6: 4),(5: 5)$.

In this study each 4 antibiotics was subjected to a broth microdilution assay and after twenty four $\mathrm{h}$ observation of bacterial growth to determine the MIC values on E.coli which shown in (Table 6).

each 5 plant extracts were subjected to a broth microdilution assay and after twenty four $\mathrm{h}$ observation of E.coli growth to determine the MIC values ,As the MIC of Rosemary is $1 \mu \mathrm{g} /$ $\mathrm{ml}$, Majoram is $4 \mu \mathrm{g} / \mathrm{ml}$, Peppermint is $64 \mu \mathrm{g}$ / $\mathrm{ml}$, Dill is $8 \mu \mathrm{g} / \mathrm{ml}$ and Neem is $32 \mu \mathrm{g} / \mathrm{ml}$.

Antimicrobial activities of methanol plant extracts in combination with antimicrobial agents on selected E.coli isolates as Interactions lead to antagonistic, additive and synergistic, as additive observed when the combined effect is equal to the sum of the individual effects, antagonism is observed when the effect of one or both compounds is less when they are applied together then Synergism is observed when the effect of the combined substances is greater than the sum of the individual ,as in (Table 8 ) as amoxycillin shows synergistic action with Rosemary by level (7:3), (6:4) and with dill by level (7:3). While doxycyclin shows synergistic action in combination of with Peppermint by level (7:3), (6:4) and by (5:5). Also gentamicin shows synergistic action in combination of with Rosemary by level (7:3), (6:4) and with dill by
(7:3), (6:4) and (5:5) and difloxacin shows synergistic action in combination of with Rosemary by level (7:3), (6:4) and (5:5).

Extraction with organic solvents is the best way to extract antioxidant according to the polarity as solvents seemed to be preferable to either nonpolar or polar solvents Pokorný et al., (2000) So the extraction was methanol $80 \%$ with ultrasonic-assisted was better solvents for extracting phenolic compounds owing to their higher polarity and good solubility Wieland et al., (2006) and also the ultrasound waves cause tissue or cell wall disruption in a short period of time, increase in solvent transfer into the biological matrix, and release of cellular content, consequently leading to higher surface mass transfer Vilkhu et al. (2008), the result showed that Neem, marjoram and rosemary had high yield with respective weights $24.8,16.2$ and $13.4 \mathrm{~g}$ extract/100 g plant also rosemary and mint had high phenolic compounds with respective values of 186.25 and $143.45 \mathrm{mg}$ GAE $\mathrm{g}^{-1}$ extract. Variation in the extraction yields is referred to the polarity of compounds found in plants Jayaprakasha et al., (2003) as during the extraction of U.M.E. The Folin-Ciocalteu method estimates the reduction of the reagent by phenolic compounds for formation a blue complex that can be measured at $763 \mathrm{~nm}$ against gallic acid equivalent (GAE) as a standard phenolic compound Imeh and Khokhar, (2002) (Table 9).

Inhibition of DPPH radicals: Antioxidants react with $\mathrm{DPPH}^{\circ}$ means reducing the number of $\mathrm{DPPH}^{*}$ free radicals to the number of their available hydroxyl groups. Therefore, the absorption at $515 \mathrm{~nm}$ is relative to the amount of residual DPPH Juan et al., (2005). It is visually noticeable as a discoloration from purple to yellow. Figure (1) represented that extracts contained high amount of total phenolic compounds showed high antioxidant activity as strong as that of TBHQ and gallic 
acid. As Heim et al., (2002) proved that antioxidant activity of plant extracts is mainly due to the concentration of phenolic compounds in the plant. The results recorded rosemary extract has the best scavenging activity of DPPH-free radical with activity $80.4 \%$ against synthetic antioxidant (TBHQ) with $94.62 \%$ and gallic acid 94.43\%.Then followed by mint, neem, marjoram and dill extracts with respective data 56.58\%, 41.88\%, $39,96 \%$ and $16.91 \%$ (Figure 1).

Table 1: No. of E.coli isolates obtained from various specimens collected from different chicken localities in Sharkia and Dakahlia governorates.

\begin{tabular}{cccc}
\hline & Locality & No. of cases & E.coli \\
\hline & Private farms & & \\
& (Mahtet Elsalam,Mahtet ElAml,Tawonya) & 19 & 25 \\
& Private farms (Gamsa,Sherbin) & 18 & 30 \\
& Farms in Sharkia governate & 29 & 44 \\
& Elsalehia project & & 21 \\
& Private farms in Sharkia governate & 13 & $79(65.8 \%)$ \\
\hline
\end{tabular}

Table 2: List of the concentration of the methanol extract obtained from leaves from different plant parts $\mathrm{g} / \mathrm{ml}$ spices in Stock solution.

\begin{tabular}{cccccc}
\hline Scientific name & Family & Local name & $\begin{array}{c}\text { Wt.of extract } \\
\text { in tube }(\mathrm{g})\end{array}$ & $\begin{array}{c}\text { Wt.of empty } \\
\text { tube }(\mathrm{g})\end{array}$ & $\begin{array}{c}\text { Total Wt.of } \\
\text { extract }(\mathrm{g})\end{array}$ \\
\hline $\begin{array}{c}\text { Rosmarinus } \\
\text { officinalis } \\
\text { Origanum } \\
\text { Majorana }\end{array}$ & Lamiaceae & Rosemary & 149.0201 & 146.3335 & 2.6 \\
$\begin{array}{c}\text { Mentha piperita } \\
\text { Anethum } \\
\text { graveolens }\end{array}$ & Lamiaceae & Peppermint & 180.0534 & 177.5157 & 2.5 \\
$\begin{array}{c}\text { Azadirachta } \\
\text { Meliaceae }\end{array}$ & Meliaceae & Neem & 138.0542 & 134.5216 & 3.5 \\
\hline
\end{tabular}


Abd El- Tawab et al. (2018). BVMJ-35(2): 107-119

Table 3: Diameter of zone of inhibition ( $\mathrm{mm}$ ) of antibiotics and Plant extracts only and combination on E.coli isolates.

\begin{tabular}{cccccccccc}
\hline Isolates & \multicolumn{8}{c}{ Inhibition zone $(\mathrm{mm})$} \\
\hline & Plant & \multicolumn{7}{c}{ Antibiotics alone } \\
E.coli & alone & Amoxy & Doxy & Genta & Diflo & Amoxy & Doxy & Genta & Diflo \\
Rosemary & $8_{ \pm 0.82}$ & $15_{ \pm 0.82}$ & --- & $13_{ \pm 0.82}$ & $19_{ \pm 0.95}$ & $19_{ \pm 0.41}$ & --- & $18_{ \pm 1.25}$ & $22_{ \pm 1.25}$ \\
Majoram & $15.2_{ \pm 1.02}$ & $15_{ \pm 0.41}$ & --- & $13_{ \pm 1.63}$ & $18_{ \pm 1.10}$ & $15_{ \pm 0.41}$ & --- & $13_{ \pm 2.05}$ & $18_{ \pm 2.05}$ \\
Peppermint & $15_{ \pm 0.82}$ & $10_{ \pm 0.62}$ & --- & $13_{ \pm 0.47}$ & $19_{ \pm 1.14}$ & $10_{ \pm 0.74}$ & --- & $13_{ \pm 0.54}$ & $18_{ \pm 1.03}$ \\
Dill & --- & $15_{ \pm 0.74}$ & $16_{ \pm 0.82}$ & $13_{ \pm 0.41}$ & $19_{ \pm 1.47}$ & $18_{ \pm 0.82}$ & $16_{ \pm 0.47}$ & $15_{ \pm 1.31}$ & $19_{ \pm 0.80}$ \\
Neem & $10_{ \pm 1.25}$ & $15_{ \pm 0.85}$ & --- & $13_{ \pm 1.10}$ & $18_{ \pm 0.77}$ & $15_{ \pm 0.62}$ & --- & $13_{ \pm 0.59}$ & $18_{ \pm 0.68}$ \\
\hline
\end{tabular}

Table 4: Summary of the Biochemical characteristics of isolated bacteria by the IMViC results of some important species.

\begin{tabular}{ccccc}
\hline Species & Indole & $\begin{array}{c}\text { Methyl } \\
\text { Red }\end{array}$ & $\begin{array}{c}\text { Voges- } \\
\text { Proskauer }\end{array}$ & Citrate \\
\hline Escherichia coli & Positive & Positive & Negative & Negative \\
Klebsiella spp. & Negative & Negative & Positive & Positive \\
Salmonella spp. & Negative & Positive & Negative & Positive \\
Shigella spp. & Negative & Positive & Negative & Negative \\
Proteus mirabilis & Negative & Positive & Negative & Positive \\
Citrobacter freundii & Negative & Positive & Negative & Positive \\
\hline
\end{tabular}

Table 5: Antimicrobial susceptibility of E.coli spp. $(n=79)$ by agar disc diffusion method.

\begin{tabular}{ccccc}
\hline Antimicrobial agents & Trade name & S & I & R \\
\hline Amoxicillin & AML & 25 & 29 & 25 \\
Colistin & CT & 38 & 30 & 11 \\
Difloxacin & DIF & 8 & 54 & 17 \\
Doxycyclin & DO & 31 & 24 & 24 \\
Gentamycin & GN & 27 & 34 & 13 \\
Erythromycin & E & -- & 21 & 58 \\
Flurophenicol & F & 24 & 42 & 13 \\
Cefotaxime & CTX & 16 & 10 & 53 \\
Streptomycin & S & 26 & 10 & 42
\end{tabular}


Table 6: Determination of Antibacterial Activity of plants extract by Minimal Inhibitory Concentration (MIC) on E.coli spp.

\begin{tabular}{|c|c|c|}
\hline \multirow[b]{2}{*}{ Plants } & \multicolumn{2}{|c|}{ E.coli isolates } \\
\hline & E.coli & $\mathrm{MIC} \mu \mathrm{g} / \mathrm{Ml}$ \\
\hline \multirow{2}{*}{ Rosemary } & Field & $1 \pm 0.41$ \\
\hline & Standard strain & $0.25 \pm 0.04$ \\
\hline \multirow{2}{*}{ Pepermint } & Field & $64 \pm 3.27$ \\
\hline & Standard strain & $16_{ \pm 1.63}$ \\
\hline \multirow{2}{*}{ Majoram } & Field & $4_{ \pm 0.82}$ \\
\hline & Standard strain & $1 \pm 0.41$ \\
\hline \multirow{2}{*}{ Dill } & Field & $8 \pm 1.25$ \\
\hline & Standard strain & $2 \pm 0.82$ \\
\hline \multirow{2}{*}{ Neem } & Field & $32 \pm 2.49$ \\
\hline & Standard strain & $8 \pm 0.82$ \\
\hline
\end{tabular}

Table 7: Determination of Antibacterial Activity of antibotics by Minimal Inhibitory Concentration (MIC) on E.coli spp.

\begin{tabular}{|c|c|c|c|}
\hline \multirow{2}{*}{ Antibiotic } & \multicolumn{3}{|c|}{ E.coli isolates } \\
\hline & \multicolumn{2}{|c|}{ E.coli } & MIC \\
\hline \multirow{3}{*}{ AML } & \multirow{2}{*}{ Field } & E.3 & $8 \pm 0.81$ \\
\hline & & E. 29 & $4_{ \pm 0.81}$ \\
\hline & \multicolumn{2}{|c|}{ Standard strain } & $1_{ \pm 0.41}$ \\
\hline \multirow{3}{*}{ INN } & \multirow{2}{*}{ Field } & E.21 & $4_{ \pm 0.81}$ \\
\hline & & E. 29 & $0.5_{ \pm 0.20}$ \\
\hline & \multicolumn{2}{|c|}{ Standard strain } & $0.125 \pm 0.02$ \\
\hline \multirow{3}{*}{ DO } & \multirow{2}{*}{ Field } & E.33 & $16_{ \pm 1.63}$ \\
\hline & & E. 29 & $4_{ \pm 0.81}$ \\
\hline & \multicolumn{2}{|c|}{ Standard strain } & $2 \pm 0.81$ \\
\hline \multirow{3}{*}{ GN } & \multirow{2}{*}{ Field } & E.40 & $4_{ \pm 0.81}$ \\
\hline & & E. 29 & $2 \pm 0.81$ \\
\hline & \multicolumn{2}{|c|}{ Standard strain } & $0.05_{ \pm 0.03}$ \\
\hline
\end{tabular}


Abd El- Tawab et al. (2018). BVMJ-35(2): 107-119

Table 8: Combination activity of antibiotics with extracts using Decimal Assay for Additivity (DAA).

\begin{tabular}{|c|c|c|c|c|c|c|}
\hline \multicolumn{7}{|c|}{ E.coli } \\
\hline \multirow{2}{*}{ Plant extracts } & \multirow{2}{*}{ antibiotics } & \multicolumn{3}{|c|}{ DAA } & \multirow{2}{*}{$\frac{\mathrm{MIC}}{\mathrm{AB} \text { alone }}$} & \multirow{2}{*}{ effect } \\
\hline & & $\mathrm{AB}$ & $\mathrm{E}$ & DAA & & \\
\hline \multirow{6}{*}{ Rosemary } & \multirow{2}{*}{ a) Amoxycillin } & 7 & 3 & 0.5 & 4 & \multirow{2}{*}{ Synergy (S) } \\
\hline & & 6 & 4 & 0.5 & 4 & \\
\hline & \multirow{2}{*}{ b) Gentamicin } & 7 & 3 & 0.5 & 2 & \multirow{2}{*}{ Synergy (S) } \\
\hline & & 6 & 4 & 0.5 & 2 & \\
\hline & & 7 & 3 & 0.06 & 0.5 & \\
\hline & c) Difloxacin & 6 & 4 & 0.125 & 0.5 & Synergy (S) \\
\hline \multirow{4}{*}{ Peppermint } & & 5 & 5 & 0.25 & 0.5 & \\
\hline & & 7 & 3 & 2 & 4 & \multirow{3}{*}{ Synergy (S } \\
\hline & a) Doxycycline & 6 & 4 & 2 & 4 & \\
\hline & & 5 & 5 & 2 & 4 & \\
\hline \multirow{4}{*}{ Dill } & a) Amoxycillin & 7 & 3 & 1 & 4 & \multirow[t]{2}{*}{ Synergy (S) } \\
\hline & \multirow{3}{*}{ b) Gentamicin } & 7 & 3 & 1 & 2 & \\
\hline & & 6 & 4 & 1 & 2 & \multirow[t]{2}{*}{ Synergy (S) } \\
\hline & & 4 & 6 & 1 & 2 & \\
\hline
\end{tabular}

Table 9: Total phenolic compounds ( $\mathrm{mg}$ gallic acid /g extract) in U.A.E and M.A.W extracts.

\begin{tabular}{cccc}
\hline plants & extract yield & \% Extract & TPC mg GAE/g extract \\
\hline Dill & 2.04 & 10.2 & $36.96_{ \pm 0.81}$ \\
Rosemary & 2.68 & 13.4 & $186.25_{ \pm 1.23}$ \\
Marjoram & 3.24 & 16.2 & $119.38_{ \pm 0.83}$ \\
Mint & 2.53 & 12.65 & $143.45_{ \pm 1.22}$ \\
Neem & 4.96 & 24.8 & $39.38_{ \pm 0.83}$ \\
\hline
\end{tabular}




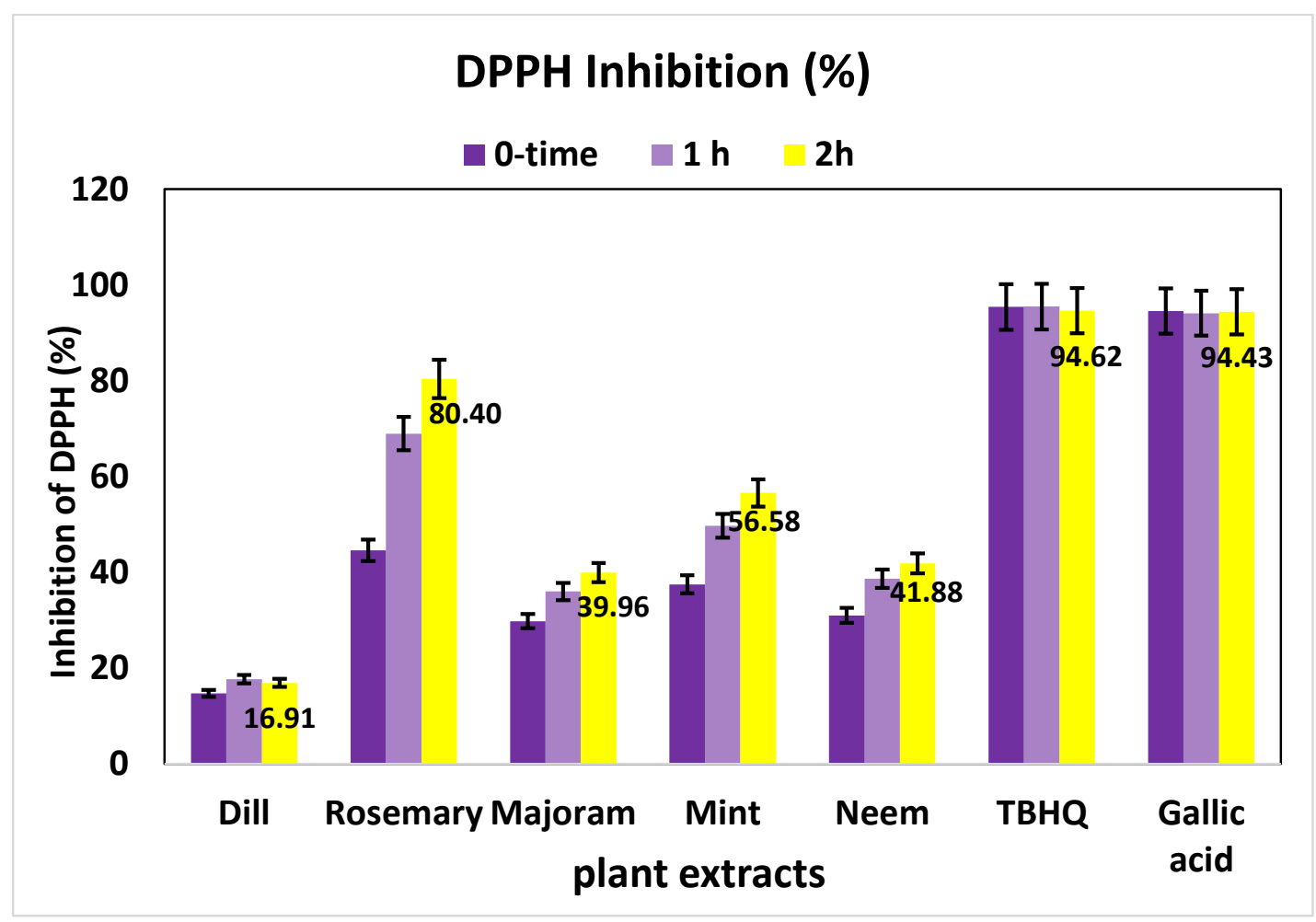

Fig.1. Antioxidant DPPH' radical-scavenging activity.

(2006) with Z.I of Rosemary ranged of (14-

\section{DISCUSSION}

E.coli infection is the major bacterial disease in poultry industry worldwide and our data are parallel to those of (Kabir, 2010) and Markov et al., (2009) who talked about $95 \%$ of E.coli are ingested through food.

Biochemical tests as IMViC with recoded results agreed with (Hendriksen, 2011).

Antimicrobial susceptibility testing on clinical veterinary E.coli strains showed results similar to other pattern of Threlfall et al., (1996) which recorded highest sensitivity rate to colistin, doxycycline and intermediate action to gentamicin and amoxicillin while the highest resistant to streptomycin.

The zone of inhibition was obtained for E.coli to show antibacterial activity of different plant extracts and antibiotics on it and the results revealed that the diameter of inhibition zone of different plant extract varied from 8 to $15 \mathrm{~mm}$, this results are disagree with Marzouk et al.,
26) $\mathrm{mm}$ in diameter, matched with (Shaza and Frdoos 2014) with Z.I of Marjoram (16) mm in diameter, also agree with reports of Hawrelal et al., (2009) with Z.I of Pepermint (17) $\mathrm{mm}$ in diameter, not accordance with previous published data with Z.I of Dill (10) $\mathrm{mm}$ in diameter. On the other hand, Neem results totally disagree with the finding of Hoque et al., (2007) who reported that extract of neem did not show antimicrobial activity against any of the Gram-negative bacteria. The synergistic interaction was determined between rosemary with amoxicillin, difloxacin and gentamicin against Escherichia coli which agree with Nazzaro et al., (2003) therefore rosemary increased the permeability of cell to antibiotics that lead to reduced the MIC when combined with gentamicin, In another study Ghusoon A, (2017) demonstrated the combination of gentamicin and ciprofloxacin with rosemary EO were increased the antimicrobial activity of these antibiotics (synergetic effect) against $E$. coli. 
Abd El- Tawab et al. (2018). BVMJ-35(2): 107-119

Our results suggested that Dill extract could be combined with antibiotics like amoxicillin and gentamicin as it has been successful in combating E.coli infection, similar results have been obtained by other researchers. Markov et al., (2009) as extracts from dill seeds shows higher antimicrobial activity on E. coli compared to amoxicillin antibiotics and this contrast with Ljiljana P. et al., (2016) which reported that dill effect was observed the highest effect on Gram-positive m.o. On the other hand in this study, doxycycline antibiotic and Mint combinations may be recommended for E.coli infections, Similarly, Tuysuz et al., (2017) examined the antimicrobial activities of 31 different herbal teas for examples (Mint) both alone and in combination with antibiotics while Lee et al., (2005), also showed that Mint and ciprofloxacin combinations were synergistic against $E$. coli.

Phenolic substances have been shown to be responsible for the antioxidant activity of plant materials Kim et al., (2011).

Higher antioxidant activity has been positively correlated with the concentration of phenolic compounds in extracts, as Rosemary and Mint had high phenolic compounds with respective values of 186.25 and $143.45 \mathrm{mg}$ GAEg/lextract.On the other hand rosemary and Mint extracts have the best scavenging activity of DPPH-free radical with activity $80.4 \%$ and $56.58 \%$ against synthetic antioxidant (TBHQ) with $94.62 \%$ and gallic acid, our obtained results were very close to data with (Bryngelsson et al., 2002; Sun et al., 2007).

\section{Conclusion}

Synergistic activity by antibiotic and plant against Gram negative bacteria demonstrated that plant can be a source of bioactive substances with broad spectrum of antibacterial activity especially when combined with antibiotic, in addition, the methanol plant extract have higher total antioxidant and phenolic compounds which used in pharmaceutical products as a source of natural antioxidants plus that more research is required to investigate the synergistic capacity of plants with antimicrobial activity.

\section{REFERENCES}

Adams, C.M., Anderson, M.G., Motto, D.G., Price, M.P., Johnson, W.A., Welsh, M. J. (1998): Ripped pocket and pickpocket, novel Drosophila DEG/ENaC subunits expressed in early development and in mechanosensory neurons. J. Cell Biol, 140(1):143-152.

AOAS (1990): In official methods and recommended practices of the American Oil Chemists Society (4th ed). Champaign: American Oil Chemists Society.

Bakkali, F., Averbeck, S., Averbeck, D., Idaomar, M (2008): Biological effects of essential oils - a review. Food and Chemical Toxicology, 46 (2): 446-475.

Bauer, A.W., Kirby, M., Kirby, J., Sherris, C., \& Turck, M. (1966): Antibiotic susceptibility testing by astandardized single disc method.Am.J. Clin Patho, 145: 493-496.

Betancourt, A.O., (2008): Analyse, extraction et récupération de poly-3 hydroxybutyrate présent dans la biomasse. Université du Québec à Montréal Thesis, pp: 45-55.

Bryngelson, S., Mannerstedt-Fogelfors, B., KamalEldin, A., Andersson, R. and Dimberg, L.H., (2002): Lipids and antioxidants in groats and hulls of Swedish oats (Avena sativa L.). J Sci Food Agric, 82: 606-614. 
Centers for Disease Control and Prevention (CDC), National Center for Health Statistics (2013): Antibiotic resistance threats in the United States, Apr. Available.

Cioffi, M.B., Martins,C., Centofante, L., Jacobina, U., Bertollo, and L.A.C.,( 2009): Chromosomal variability among allopatric populations of Erythrinidae Fish Hoplias malabaricus: mapping of three classes of repetitive DNAs. Cytogenet Genome Res., 125: 132-141.

Delaquis, P.J., Stanich, K., Girard, B.,\&Mazza, G.(2002): Antimicro bialactivity of individual and mixed fractions of dill, cilantro,c oriander and eucalyptus essential oils. Int. J. Food Microbiol, 74:101-109.

Dikilitas, M., Guldur, M.E., Deryaoglu, A. and Erel, O., (2011): Anti-oxidant and oxidant levels of pepper (Capsicum annuum cv. 'Charlee') infected with pepper mild mottle virus. Not. Bot. Horti Agrobo, 39: 58-63.

Dorman, H., \& Deans, S., (2000): Antimicrobial agents from plants, antibacterial activity of plant volatile oils. Journal of Applied Microbiology 88: 308-316.

Enayat, K., Mansour, A., Nasrin, B., Mohammad, T., Eze, H., Oruche, E. and Eze, N. (2013).Interaction of the extracts of three medicinal plants with antibiotics against some antibiotic resistant bacteria. Academic Journals, 8(28):1360-1367.

Eze, E.A., Oruche, N.E., Onuora, V.C. and Eze CN., (2013). Antibacterial Screening of Crude Ethanolic leaf Extracts of Four Medicinal Plants. J. Asian Sci. Res, 3(5):431-439
Gavarić, N.,Gavarić, J.,Kovač, N.,Kretschmer, N., Kladar, S., Možina, F.,\& Bucar.(2015).Natural products as antibacterial agents antibacterial potential and safety of post-distillation and waste material from Thymus vulgaris L., Lamiaceae .Journal of Essential Oil-Bearing Plants, 10.1080/0972060X.2015.971069

Ghusoon A. Abdulhasan (2017). Synergism effect of rosemary essential oil and some antibiotic against Escherichia coli isolated from clinical samples IOSR Journal of Pharmacy and Biological Sciences (IOSR-JPBS), Volume (12), 2:39-42.

Gulcin, I., Kufrevioglu, O.I., Oktay, M., \&Buyukokuroglu, M.E. (2004). Antioxidant, antimicrobial, antiulcer and analgesic activities of nettle (Urtica dioica L.). J. Ethnopharmacolo, 90: 205-215.

Handa,S.S., Khanuja, S. P. S., Longo, G., Rakesh, D.D. (2008): Extraction Technologies for Medicinal and Aromatic Plants, (1stedn), no. 66. Italy: United Nations Industrial Development Organization and the International Centre for Science and High Technology. Trieste.

Harley, J.P. \& Prescott, L.M., (2002): Laboratory exercises in Microbiology. 5th ed. McGraw-Hill companies, USA. Pp: 133-192.

Heim, K.E.,Taigliaferro, A.R.\& Bobilya, D.J. (2002): Flavonoid antioxidants: chemistry, metabolism and structureactivity relationships. J. Nutr. Biochem., 13:572-584.

Hendriksen, R.S.,Vieira, A.R., Karlsmose, S., Lo-Fo-Wong, D.M., Jensen, A. B., 
Abd El- Tawab et al. (2018). BVMJ-35(2): 107-119

\&Wegener, H.C.(2011): Global monitoring of Salmonella serovar distribution from the world health organization global foodborne infection network country databank 2007. FoodbornePathog.Dis. 8: 887-900.

Hoque, M.D.M., Bari, M.L., Inatsu, Y., Juneja, V.K., \& Kawamoto, S. (2007): Antibacterial Activity of Guava (Psidium guajava L.) and Neem (Azadirachta idica A. Juss). Extracts Against Foodborne Pathogens and Spoilage Bacteria. Foodborne Pathogens and Disease, (4):481-488.

Imeh, U. and Khokhar, S. (2002): Distribution of conjugated and free phenols in fruits: antioxidant activity and cultivar variations. J. Agric. Food Chem., 50:6301-6306.

Jayaprakasha, G.K., Rao, L.J.M., \&Sakariah K.K., (2003): Volatile constituents from Cinnamomum zeylanicum fruit stalks and their antioxidant activities. J Agric Food Chem, 5(15):4344-4348.

Juan, X., Shubing, C. and Qiuhui, H. (2005): Antioxidant activity of brown pigment and extracts from black sesame seed (Sesamum indicum L.). Food Chem., 91:79-83.

Kabir, S.M.L. (2010): The Role of probiotics in the poultry industry. Int. J. Mol. Sci, (10):3531-3546.

Kim, I.S., Yang, M.R., Lee, O.H., Kang, S.N., (2011): Antioxidant activities of hot water extracts from various spices. Int $\mathrm{J}$ Mol Sci, 12: 4120-31.

Lee, Y.S., Han, C.H., Kang, S.H., Lee, S.J, Kim S.W, Shin O.R, Sim Y.C., Lee, S.J, \&Cho, Y.H. (2005): Synergistic effect between catechin and ciprofloxacin on chronic bacterial prostatitis
ratmodel.International Journal of Urology, (12):383-389.

Ljiljana, P.,Stanojević.,Mihajlo, Z.,Stanković, Dragan, J.,Cvetković, Bojana, R., Danilović, J., Stanojević S., Singh, P., \&Prakash, A., (2016): Dill (Anethum graveolens $L$.) seeds essential oil as a potential natural antioxidant and antimicrobial agent biological nyssana 7 (1) September , 31-39

Lorian, V., (1996). Antibiotics in Laboratory Medicine. 4th Edn., Williams and Wilkins, Baltimore, London, ISBN: 9780781749831.

Markov, K., Frece, J., Čvek, D., Delaš, F. (2009).Listeria monocytogenes i drugi kontaminanti u svježem siru i vrhnju domaće proizvodnje s područja grada Zagreba. Mljekarstvo, 59 (3):225-231.

Marzouk, Z., Neffati, A.; Marzouk, B., Chraief, I., Fathia, K., Chekir, G., \& Boukef, K. (2006).Chemical composition and antibacterial and antimutagenic activity of Tunisian Rosmarinus officinal is L. oil from Kasrine. J. of Food, Agric. \& Environment, 4(3\&4): 61-65.

Mounia,T.L.,Shuo,H.,Sean,T.,Corbett1.,JeanF rancois,L.,Svetlana,Y.,Lindsay,M.,Mey ers3.,Chad,A.,Shaw3.,Sung,Hae,L.,Ka ng., Sau,W.C., Dolores. and Lamb1,J. (2010): Identification of De Novo Copy Number Variants Associated with Human Disorders of Sexual Development. Oxoid Ltd, Basingstoke, Hampshire, UK.

Nazzaro, F., Fratianni, F., De Martino, L., Coppola, R. \& De Feo, V. (2003): Effect of Essential Oils on Pathogenic Bacteria. Pharmaceutic, 6(12):14511474. 
Pokorny, J., Yanishlieva, N. and Gordon M (2000): Antioxidants in food.Practical applications. Published in North and South America by CRC Press LLC, Corporate Blvd, NW Boca Raton FL 33431, USA.

Sanders, CC., Sanders, W.E. and Moland, E.S. (1993): Decimal assay for additvity of drugs permits delineation of synergy and antagonism.Antimicrob. Agents Chemother; 37: 260-264.

Shaza anwar AL-laham and Frdoos mohammad AL-fadel (2014). Screening the antimicrobial activity of some medical plants against multidrugs resistance Escherichia coli type (1) Asian, J Pharmaceut Res Health Care, (6) Issue 1.

Singleton,V.L.,\&Rossi,J.A.(1965).Colorimetr $\mathrm{y}$ of total phenolics with phosphomolybdic phosphotungstic acid reagents. Am J Enol Viticult. 16:144158

Skerget, M.,Kotnik, P., Hadolin, M., RiznerHras, A., Simonic, M., \& Knez, Z. (2005): Phenols, proanthocyanidins, flavones and flavonols in some plant materials and their antioxidant activities. Food Chem., 89:191-198.

Stefanovic, O.\&Comic, L.(2012): Synergistic Antibacterial Interaction between Melissa officinalis extracts and antibiotics. J.Appl.Pharmaceut.Sci, 2(1), 1-5.

Sun, T., Xu, Z.,Wu, C.T., Janes, M., Prinyawiwatkul W (2007): Antioxidant activities of different colored sweet bell peppers (Capsicum annuum L.). J Food Sci, 72: 98-102.

Threlfall, E.J., Frost, J.A., Ward, L.R., \&Rowe, B., (1996): Increasing spectrum of resistance in multiresistant Salmonella-typhimurium.Lancet, 347:1053-1054.

Tuysuz, et al., (2017): Antimicrobial activities of widely consumed herbal teas, alone or in combination with an-tibiotics: an in vitro study.PeerJ, 5:e3467; DOI 10.7717/peerj.3467

Valko, M., Rhodes, CJ., Moncol, J., \& Izakovic M.(2006): Free radicals, metals and antioxidants in oxidative stress-induced cancer. Mini-review. Chem. Biol. Interact, 160:1-40.

Vilkhu, K., Mawson, R., Simons, L., and Bates, D. (2008): Applications and opportunities for ultrasound assisted extraction in the food industry-A review. Innov Food SciEmerg Technol, 9(2):161-169.

Wieland, P., Ferran, S., Wilfried, D., Andreas, P., Irene, G., \&Diego, J. (2006): An industrial approach in the search of natural antioxidants from vegetable and fruit wastes. Food Chem., 97:137-150.

Zhao Y. and Gao Y. (2014): Self-processing of ribozyme-flanked RNAs into guide RNAs in vitro and in vivo for CRISPRmediated genome editing. J Integr Plant Biol. Apr; 56(4):343-349. 